\title{
Colored selective absorber coating with excellent durability
}

\author{
Atasi Dan, ${ }^{\text {a, }}$ Kamanio Chattopadhyay, ${ }^{\text {b,c }}$ Harish C. Barshilia, ${ }^{\text {d }}$ Bikramjit Basu ${ }^{\text {a,b }}$
}

\begin{abstract}
The colored solar-thermal collectors can provide advantages of architectural integration over energy performance. The colour appearance of the solar-thermal collectors can be achieved by increasing the number of layers. W/WAlN/WAlON/ $/ \mathrm{Al}_{2} \mathrm{O}_{3}$ coating, fabricated by $\mathrm{DC}$ and RF magnetron sputtering showed a high solar absorptance of 0.948 and the low thermal emittance of 0.08 with a sky blue color appearance. The tandem absorber exhibited excellent long-term thermal stability at $500{ }^{\circ} \mathrm{C}$ in air for $100 \mathrm{hrs}$. The absorber deposited on SS substrates showed high solar selectivity $(\alpha / \varepsilon)$ of $0.918 / 0.11$, even after heat treatment in air up to $500^{\circ} \mathrm{C}$ for $100 \mathrm{hrs}$. The selective performance of the coating can be stable more than 25 years. The humidity test confirms the significant moisture resistant of the coating. In summary, the new W/WAlN/WAlON/ $\mathrm{Al}_{2} \mathrm{O}_{3}$-based coating with its colourful appearance is appropriate to be used in solar thermal collectors.
\end{abstract}

Key words: Solar-thermal collectors, colored coatings, spectral selectivity, optical properties, thermal stability

\section{Introduction}


The solar energy is the most popular alternative source of energy to supply world's expanding needs of energy without environmental detriment. The solar-thermal power systems can efficiently transform the solar energy to heat or electricity. The flat plate collectors are most widely used solar thermal power systems for residential or commercial water heating [1]. Spectrally selective absorbers are very important in solar water heaters to improve the efficiency of the solar-thermal systems. The desired properties of the spectrally selective absorbers are high absorptance in the solar spectrum range $(0.25-2.5 \mu \mathrm{m})$ and less emittance in the infrared region $(2.5-25 \mu \mathrm{m})$ [2]. The absorptance is an optical characteristics which depends on the intrinsic property of the materials and the structure of thin film of the selective coatings whereas low thermal emittance is dependent on the metallic substrates. The flat plate collectors are usually prepared black in colour to achieve highest absorption of solar energy. In order to improve the aesthetic appearance of building roofs and facades, it is important to deposit the colourful solar selective coating on the flat plate collectors keeping high performance at the same time [3]. These coating should possess high selective performance in an elevated temperature. The spectrally selective coloured paints are one of the well-known approaches to fabricate the colored solar selective absorbers coatings. The only thing that limits the use of spectrally selective coloured paints is the high emittance. The thermal emittance of the paint coatings are $>20 \%$ due to high thickness $(>1 \mu \mathrm{m})[4]$. There is a newer approach to deposit the solar selective absorber coating in which the metallic property of the layers decreases from bottom to top. These selective coatings consist of four layers from substrate to substrate (1) an infrared metallic reflector, (2) an absorber layer with higher metallic content, (3) a semi-transparent layer with lower metallic content and (4) a dielectric on top as an anti-reflection layer [5]. Such a colored tandem absorber with high absorptance and low thermal emittance can be used in the collectors. 
In our previous work, we have deposited W/WAlN/WAlON/ $\mathrm{Al}_{2} \mathrm{O}_{3}$-based solar selective coating by DC and RF magnetron sputtering. The W layer is pure metallic whereas the $\mathrm{Al}_{2} \mathrm{O}_{3}$ layer is dielectric in nature. The metallic property of WAlN and WAlON was tailored by varying the amount of $\mathrm{O}_{2} / \mathrm{N}_{2}$ in the film such that WAlON has less metallic character than WAIN. The coating exhibited a high absorptance of 0.948 and a low thermal emittance of 0.08. In addition, we have investigated the short-term thermal stability of the coating from $300-550{ }^{\circ} \mathrm{C}$ in air for 2 hrs. The coating showed very high thermal stability up to $500{ }^{\circ} \mathrm{C}$ in air for $2 \mathrm{hrs}$ Long term thermal stability is a very critical issue for photo thermal applications. The coating exhibited excellent thermal stability upto $350{ }^{\circ} \mathrm{C}$ in air for $550 \mathrm{hrs}$. The details of the work can be found elsewhere $[6,7]$.

In the present work, we report the role of individual layer with appropriate properties to produce a color appearance of the coating. The absorptance, emittance and associated colorimetric data of these coatings are discussed. In addition, the long-term (150 hrs) high temperature stability of the coating at $500{ }^{\circ} \mathrm{C}$ in air has been investigated. The colour appearance of the coating after the prolonged heat treatment has also been studied. In order to evaluate the moisture resistance of the coating, humidity test has been carried out for $50 \mathrm{hrs}$ at $40{ }^{\circ} \mathrm{C}$ condensation.

\section{Experimental details}

The W/WAlN/WAlON/ $/ \mathrm{Al}_{2} \mathrm{O}_{3}$ has been deposited by DC/RF magnetron sputtering using $\mathrm{W}, \mathrm{Al}$ and $\mathrm{Al}_{2} \mathrm{O}_{3}$ targets with a purity of $99.99 \%$. The substrates were polished mechanically for a longer time to obtain a very less roughness $(3.23 \mathrm{~nm})$. The polishing of the substrate is very crucial for fabrication of solar selective absorber coating as the emissivity of the coating depends on the substrate roughness. The substrates were cleaned with detergent and flushed with de-iodized water. Finally these were ultrasonicated for 15 mins in absolute ethanol, acetone separately. Before starting the deposition, the sputtering chamber was 
pumped down to a base pressure of $8.5 \times 10^{-6}$ mbar by a rotary pump backed by turbomolecular pump. The deposition of W layer was performed in Ar atmosphere. The $\mathrm{W}$ and $\mathrm{Al}$ targets run simultaneously in $\mathrm{Ar}, \mathrm{N}_{2}$ and $\mathrm{O}_{2}$ environment to deposit WAlN and WAlON layers. The $\mathrm{Al}_{2} \mathrm{O}_{3}$ layer has been deposited using $\mathrm{Al}_{2} \mathrm{O}_{3}$ target in $\mathrm{Ar}+\mathrm{O}_{2}$ environment. The design of the coating has been presented in Fig. 1.

\subsection{Optical characterization}

The absorptance $(\alpha)$ of the coating can be defined by the ratio of the amount of energy absorbed by the coating to the total incident radiation while the emittance $(\varepsilon)$ weighted fraction between the emitted radiation from the sample and the perfect blackbody, and both can be determined in terms of the reflectance $(R(\lambda))$ using the following equations [8]:

$$
\begin{aligned}
& \alpha=\frac{\int_{0.3}^{2.5}[1-R(\lambda)] I_{S}(\lambda) d \lambda}{\int_{0.3}^{2.5} I_{S}(\lambda) d \lambda} \\
& \varepsilon=\frac{\int_{2.5}^{25}[1-R(\lambda)] I_{b}(\lambda, t) d \lambda}{\int_{2.5}^{25} I_{b}(\lambda, t) d \lambda}
\end{aligned}
$$

Where $\lambda$ is the wavelength, $R(\lambda)$ is the reflectance at $\lambda, \operatorname{Is}(\lambda)$ is the solar spectral radiation at and $\mathrm{I}_{\mathrm{b}}(\lambda, \mathrm{t})$ is the black body spectral radiation, $\mathrm{t}=80{ }^{\circ} \mathrm{C}$ is used for the normal temperature solar-thermal application. The finite integral limit has been considered in the range of 0.25 to $2.5 \mu \mathrm{m}$ and 2.5 to $25 \mu \mathrm{m}$ for solar radiation spectrum and infrared radiation spectrum, respectively.

The total hemispherical absorptance and total hemispherical emittance of the tandem absorber were measured using solar spectrum reflectometer and emissometer (M/s. Devices and Services). The absorptance of the coatings was measured at room temperature. The coating was illuminated by a tungsten-halogen lamp. The reflected rays from the samples were detected at an angle of reflection of $20^{\circ}$ using four filtered detectors. The solar spectrum measurement was achieved by summing the output from these four detectors in appropriate 
proportion. The emissometer has been used to measure the total hemispherical emittance of absorber coatings used for flat plate solar thermal collector. The maximum working temperature of the collector is $82^{\circ} \mathrm{C}$. The instrument was calibrated using standard samples. The absorptance and the emittance values were measured at four different positions and the average values of these measurements has been considered. The optical properties of the coating has been characterized by UV-Vis-NIR spectrophotometer (Perkin Elmer) from 300 $2500 \mathrm{~nm}$ in near normal incident angle. $\mathrm{BaSO}_{4}$ was used as reference sample to measure the diffuse reflectance. Basically this instrument is divided into two spectral ranges from 0.25 to $0.8 \mu \mathrm{m}$ and 0.8 to $2.5 \mu \mathrm{m}$ with the source of deuterium and tungsten lamps. The colour appearance of the heat treated samples were also studied by the color software.

To investigate the long-term thermal stability of the coating, the samples were subjected to keep at $500{ }^{\circ} \mathrm{C}$ in air for 150 hours inside a muffle furnace. The temperature of the coating was increased at a rate of $3{ }^{\circ} \mathrm{C} / \mathrm{min}$. The structural change of the annealed coating has been evaluated using XRD. To conduct the humidity test, the samples were kept at $40{ }^{\circ} \mathrm{C}$ under condensation for $50 \mathrm{hrs}$. The optical properties of the samples after annealing and humidity test were also examined by UV-Vis-NIR spectrometer.

\subsection{Color version:}

The colours of the samples are numerically specified in a plane described by a set of tristimulus values $\mathrm{X}, \mathrm{Y}, \mathrm{Z}$ in $\mathrm{CIE}$ chromaticity diagram. The $\mathrm{X}, \mathrm{Y}$ and $\mathrm{Z}$ values are calculated from three similar integration of the spectral power distribution of light $\mathrm{P}(\lambda)$ emitted from a coloured object, using the following equations,

$$
\begin{aligned}
& X=\int P(\lambda) x(\lambda) d \lambda \\
& Y=\int P(\lambda) y(\lambda) d \lambda \\
& Z=\int P(\lambda) z(\lambda) d \lambda
\end{aligned}
$$


Where $\lambda$ is the wavelength. $x(\lambda), y(\lambda)$ and $z(\lambda)$ are the set of CIE-1931 standard spectrum tristimulus values. The $\mathrm{P}(\lambda)$ can be represented as a $R(\lambda)$, measured from the reflectance spectra for a neutral light source.

$P(\lambda)=R(\lambda)$

The colour coordinates $\mathrm{x}, \mathrm{y}$ and $\mathrm{z}$ can therefore be calculated by the following equations,

$$
\begin{aligned}
& x=\frac{X}{X+Y+Z} \\
& y=\frac{Y}{X+Y+Z} \\
& z=1-(x+y)
\end{aligned}
$$

The colours can be determined by combing a given set of three primary colours, such as red, blue and green. Then, any colour can be provided in the three-point gamut in the chromaticity diagram [9].

\section{Results and Discussions:}

Essentially, the performance of a selective coating is determined by two parameters such as absorptance and emittance. The important aspect of the present work is the color tuning of the solar selective absorber coating during the deposition of consecutive layers. It is desirable to obtain a color appearance of the coating for photo-thermal applications keeping high selective properties. In practice, it is very challenging to satisfy both the conditions simultaneously. We have successfully prepared a colourful selective coating of WAlN/WAlON/Al ${ }_{2} \mathrm{O}_{3}$ with a very high absorptance of 0.948 and low emittance of 0.08 . The color appearance of the selective coating can be analysed based on the reflectance spectra of the coatings in visible range, which are shown in Fig. 2. The reflectance spectra in the visible wavelength is influenced by the absorption of light in the multilayer coating due to the interband electronic transitions. The high absorptance of the multi-layer stack can also be 
explained by the interference phenomenon between different layers in the coating. Due to the destructive interference, two interfering waves are trapped inside the multilayer which enriches the absorptance. The absorptance and emittance of pure stainless steel substrate is 0.387 and 0.12 . The deposition of the successive layers on SS such as W, WAlN, WAlON, $\mathrm{Al}_{2} \mathrm{O}_{3}$ boost the absorptance to 0.948 . WAIN layer increased the absorptance of the coating to 0.753. The deposition of WAlON layer enhanced the absorptance of the coating to 0.902 further. Finally the absorptance reaches a value of 0.948 after deposition of $\mathrm{Al}_{2} \mathrm{O}_{3}$, as an antireflection layer. The reflectance spectra of the individual layer also is in good agreement with the absorptance value of W/WAlN/WAlON/Al ${ }_{2} \mathrm{O}_{3}$. The Fig. 2 indicates that the deposition of subsequent layers decreases the reflectance of the coating. The wider minima in the reflectance spectra of W/WAlN/WAlON/ $/ \mathrm{Al}_{2} \mathrm{O}_{3}$-based coating at 870 to $1345 \mathrm{~nm}$ represents the destructive interference which helps to exhibit highest maximum for the multilayer absorber. The detail explanation of the absorptance mechanism of W/WAlN/WAlON/ $\mathrm{Al}_{2} \mathrm{O}_{3}$ can be found elsewhere [7]. The thermal emittance is determined mainly by the $\mathrm{W}$ layer. After deposition of $\mathrm{W}$ layer, the thermal emittance is maintained at 0.08 for all other layers.

Reflectance of the multilayer coating in the solar spectrum should be less for high absorptance, but it is also necessary to enhance the reflection in the visible wavelength range i.e. $380-780 \mathrm{~nm}$ to ensure the color appearance of the selective absorber. Therefore, we need to inevitably compromise the absorptance value to achieve a colourful coating. A number of studies have been reported explaining the effect of different parameters such as thickness, rate of gas flow, anti-reflection layer on the color of a selective coating $[3,9,10]$. In the present investigation, we have studied how number of layers has been optimized so that the sample exhibit a color in the visible spectral region. We have tuned the no of layers in such a way so that we can prepare a coating of sky blue in color. The reflectance spectra of the individual layer also suggests us that the colour of the tandem absorber coatings are 
highly sensitive to the no of layers. For the W layer (Fig. 2a), only one interference minimum was observed, which is located at about $465 \mathrm{~nm}$, and no peaks were found in the visible wavelength range. The surface appears grey because of the $57 \%$ reflectance in the visible wavelength range. When the WAlN layer was incorporated on top of W surface, no change in the number of interference minimum has been observed. However (Fig. 2b) a shift of the interference minimum towards the higher wavelength side occurs. The interference mimimum for W/WAIN has shifted to $1258 \mathrm{~nm}$ with a reflectance of $20 \%$. The colour of the W/WAlN sample is also grey as no interference peak is present in the visible wavelength range. After deposition of WAlON layer, a sudden change has been observed in the reflectance spectra of the coating in Fig. 2c. Two interference minima at 360 and $1293 \mathrm{~nm}$ have been found in the solar wavelength range. The colour of the sample become slightly yellowish. The reason of this colour change can be attributed to the fact that the reflectance of the coating in visible range is almost $<10 \%$ for W/WAlN/WAlON sample. In addition, the WAlON has extended the absorption of the coating up to $1293 \mathrm{~nm}$ by decreasing the reflectance. With the deposition of $\mathrm{Al}_{2} \mathrm{O}_{3}$ layer, an interference maximum has been observed at $485 \mathrm{~nm}$ and this results the bluish appearance of the coating (Fig. 2d). The reflectance at the interference maximum is about $17 \%$. The antireflection dielectric layer helps to decrease the reflectance all over the solar spectrum except an interference maximum in the visible wavelength range i.e. at $485 \mathrm{~nm}$. Finally, a peak in the visible region has been achieved by increasing the number of layers. The thickness of the entire coating is $160 \mathrm{~nm}$ where WAlN, WAlON, $\mathrm{Al}_{2} \mathrm{O}_{3}$ layers have a thickness of $~ 87,50,23 \mathrm{~nm}[7]$.

In order to understand the color change of SS/W/WAlN/WAlON/ $/ \mathrm{Al}_{2} \mathrm{O}_{3}$, the colors of the layer-added coatings are shown in the CIE chromaticity diagram (Fig. 3.) and table 1. The point, located at $\mathrm{x}=\mathrm{y}=0.33$ is known as neutral point as the reflectance in the visible wavelength range has equal value for that point. The colour at the location is white, black or 
grey. The location of the $\mathrm{W}$ and W/WAIN sample is very close to the neutral point as no interference peak has been observed in the visible range for these coatings. After deposition of WAION layer, the sample colour turns remarkably different. The colour of the coating turned to yellowish. The last layer of this design is more sensitive than other layers in color appearance. The $\mathrm{Al}_{2} \mathrm{O}_{3}$ layer changed the colour of the coating entirely from yellowish to sky blue. The dominating interference peak at $485 \mathrm{~nm}$ in the visible region gives such strong color appearance.

The W/WAlN/WAlON/ $\mathrm{Al}_{2} \mathrm{O}_{3}$ coating not only exhibited the color appearance, but also an excellent long- term thermal stability at $500{ }^{\circ} \mathrm{C}$ in air. The absorptance and the emittance of the as-deposited coating was 0.948 and 0.08 , respectively. After heat treatment at $500{ }^{\circ} \mathrm{C}$ for $150 \mathrm{hrs}$, the absorptance and the emittance changed slightly to 0.912 and $0.11(\Delta \alpha=0.036$; $\Delta \varepsilon=0.03$ ), respectively. The variation of the absorptance and emittance value with respect to annealing time has been presented in Fig 4a. According to international Energy Agency, the Performance Criterion (PC) of a flat plate collector can be expressed in terms of a change in the absorptance $(\Delta \alpha)$ and emittance $(\Delta \varepsilon)$ values by the following relation [4]:

$$
P C=-\Delta \alpha+0.25 \Delta \varepsilon \leq 0.05
$$

This relationship indicates the average life time of the flat plate collector for at least 25 years with a decrease in annual solar fraction $5 \%$. In the present case, the performance criteria value is 0.043 , which does not exceed 0.05 . Therefore, it can be stated that the service life time of W/WAlN/WAlON/ $\mathrm{Al}_{2} \mathrm{O}_{3^{-}}$based solar thermal collector can exceed 25 years.

The reflectance spectra of the as-deposited and heat treated coating for 20, 60, 80 and 100 and 150 hrs has at $500{ }^{\circ} \mathrm{C}$ in air have been presented in Fig. 4b. A small change has been observed in the reflectance spectra of the heat treated coating with respect to as-deposited coating. The negligible change in the reflectance spectra is also evident from the absorptance 
value obtained from the reflectometer. To investigate the high temperature annealing effect on the composition of the coating, we have studied the XRD spectra of the as-deposited and heat treated coating (see Fig. 5.) and we have also compared the spectra with our previous work where the coatings were annealed at $350{ }^{\circ} \mathrm{C}$ for $550 \mathrm{hrs}$ [6]. The as-deposited coating shows a high intensity and a low intensity peaks at interplanar spacings of $2.238 \AA$ and 1.582 $\AA$ respectively, corresponding to the crystallographic plane (110) and (200) of tungsten. Another peak at an interplanar spacing of $2.520 \AA$ can be attributed to crystallographic plane (111) of cubic AlN. The heat treated coating shows an additional peak which can be attributed to the (110) plane of $\mathrm{WO}_{3}$ with an interplanar spacing of $3.728 \AA$. The partial oxidation of $\mathrm{W}$ causes the formation of $\mathrm{WO}_{3}$.

There are several reasons to explain the high temperature stability of the coating The $\mathrm{Al}_{2} \mathrm{O}_{3}$ with high thermal and chemical stability act as the protection layer of the underneath coating. In addition, the $\mathrm{W}$ as diffusion layer restricts the diffusion of the $\mathrm{Fe}, \mathrm{Cr}$ atoms from stainless steel substrates towards the coating. Moreover the component of the coatings, such as $\mathrm{WN}, \mathrm{AlN}, \mathrm{AlON}$ are very stable which helps to protect the coating from degradation [11, 12]. The $\mathrm{XRD}$ data confirms the formation of $\mathrm{WO}_{3}$ during heat treatment of the coating at high temperature. It has been reported that the oxide layer has better resistance to prevent the oxygen diffusion than oxide and oxynitride layers [13]. Therefore, the formation of $\mathrm{WO}_{3}$ along with the presence of $\mathrm{Al}_{2} \mathrm{O}_{3}$ on top layer protect the underlying layers from further oxidation. The nano-crystalline and amorphous nature of the layers without grain boundary also prevent the delamination of the coatings.

In addition, interface of the four layers of the coating prevents the formation of any pinholes or cracks inside the coating. Therefore, the diffusion of the unwanted atoms from air of stainless steel substrate has been blocked [14]. The CIE points in Fig. 6 of all the heattreated coatings overlap with the point corresponds to as-deposited coating. Therefore, it can 
be concluded that the color of the absorber coating has not been changed even after long-heat treatment.

The humidity test on the coatings have not showed any adverse effect on the optical properties of the coatings. Fig. 7. represents the reflectance spectra of the coating before and after humidity test. A small change has been observed in the reflectance spectra of the coating after humidity test. Therefore it can be concluded that the humid environment has not significantly affected the selective property of the coating which confirms the excellent moisture resistance property of the environmentally stable coating.

\section{Conclusions:}

In an effort to develop a colored flat plated collector, W/WAlN/WAlON/ $\mathrm{Al}_{2} \mathrm{O}_{3}$ absorber coating was developed by DC and RF sputtering on stainless steel substrates. The effect of each layer on changing the color of the coating has been discussed. The coating showed outstanding thermal stability at $500{ }^{\circ} \mathrm{C}$ in air for 100 hrs. Long-term thermal stability tests demonstrated that the predicted service lifetime of the coatings is more than 25 years. The color of the absorber coating does not change after long-term annealing. The humidity test on the coating ascertain the extreme suitability of the coating for practical applications. Taken together, W/WAlN/WAlON/ $\mathrm{Al}_{2} \mathrm{O}_{3}$ coating shows high aesthetic compatibility, high temperature stability and moisture resistance as solar thermal collectors for building integrations.

\section{Acknowledgement}

The authors want to thank Mr. Srinivas for UV-Vis-NIR measurements. The authors acknowledge J. Jyothi for her help in sample preparation. This paper is based upon work supported in part under the US-India Partnership to Advance Clean Energy-Research (PACER) for the Solar Energy Research Institute for India and the United States (SERIIUS), funded 
jointly by the U.S. Department of Energy (Office of Science, Office of Basic Energy Sciences, and Energy Efficiency and Renewable Energy, Solar Energy Technology Program, under Subcontract DE-AC36-08GO28308 to the National Renewable Energy Laboratory, Golden, Colorado) and the Government of India, through the Department of Science and Technology under Subcontract IUSSTF/JCERDC-SERIIUS/2012 dated 22nd Nov. 2012. Atasi Dan thanks DST for providing INSPIRE scholarship.

Table 1

Color co-ordinates of successive layers

\begin{tabular}{|c|c|c|c|}
\hline Layers & X & Y & Color appearance \\
\hline W & 0.33 & 0.33 & Grey \\
\hline W/WAIN & 0.32 & 0.32 & Grey \\
\hline W/WAIN/WAION & 0.46 & 0.41 & Yellowish \\
\hline W/WAIN/WAION/AI $\mathbf{O}_{3}$ & 0.30 & 0.34 & Sky blue \\
\hline
\end{tabular}

\section{List of figures}

Fig. 1. Schematic of the design of W/WAlN/WAlON/Al ${ }_{2} \mathrm{O}_{3}$-based solar selective absorber coating

Fig. 2. Reflectance spectra of a) W; b) W/WAlN; c) W/WAIN/WAlON; d) W/WAlN/WAlON/ $/ \mathrm{Al}_{2} \mathrm{O}_{3}$ layer

Fig. 3. Chromaticity diagram layer-added absorbing coatings

Fig. 4. a) Variation of absorptance and emittance value with respect to annealing duration; 
b) Reflectance spectra of the as-deposited and heat treated coating at $500{ }^{\circ} \mathrm{C}$ in air for different time

Fig. 5. XRD spectra of as-deposited and heat treated coatings

Fig. 6. Chromaticity diagram of as-prepared and heat-treated absorbing coatings

Fig. 7. Reflectance spectra of the coating before and after humidity test

\section{References:}

[1] Q.-C. Zhang, Recent progress in high-temperature solar selective coatings, Solar energy materials and solar cells, 62 (2000) 63-74.

[2] N. Selvakumar, H.C. Barshilia, Review of physical vapor deposited (PVD) spectrally selective coatings for mid-and high-temperature solar thermal applications, Solar energy materials and solar cells, 98 (2012) 1-23.

[3] F. Chen, S.-W. Wang, X. Liu, R. Ji, Z. Li, X. Chen, Y. Chen, W. Lu, Colorful solar selective absorber integrated with different colored units, Optics express, 24 (2016) A92-A103.

[4] C.E. Kennedy, Review of mid-to high-temperature solar selective absorber materials, National Renewable Energy Laboratory Golden Colorado2002.

[5] N. Selvakumar, N.T. Manikandanath, A. Biswas, H.C. Barshilia, Design and fabrication of highly thermally stable $\mathrm{HfMoN} / \mathrm{HfON} / \mathrm{Al} 2 \mathrm{O} 3$ tandem absorber for solar thermal power generation applications, Solar Energy Materials and Solar Cells, 102 (2012) 86-92.

[6] A. Dan, K. Chattopadhyay, H.C. Barshilia, B. Basu, Angular solar absorptance and thermal stability of W/WAIN/WAION/ $/ \mathrm{Al}_{2} \mathrm{O}_{3}$-based solar selective absorber coating, Applied Thermal Engineering, DOI (2016).

[7] A. Dan, J. J, K. Chattopadhyay, H.C. Barshilia, B. Basu, Spectrally selective absorber coating of WAIN/WAION/ $/ \mathrm{Al}_{2} \mathrm{O}_{3}$ for solar thermal applications, Solar Energy Materials and Solar Cells, DOI (2016 (accepted)).

[8] A. Amri, Z.T. Jiang, T. Pryor, C.-Y. Yin, S. Djordjevic, Developments in the synthesis of flat plate solar selective absorber materials via sol-gel methods: A review, Renewable and Sustainable Energy Reviews, 36 (2014) 316-328.

[9] Y. Wu, W. Zheng, L. Lin, Y. Qu, F. Lai, Colored solar selective absorbing coatings with metal Ti and dielectric AIN multilayer structure, Solar Energy Materials and Solar Cells, 115 (2013) 145-150.

[10] G.K. Dalapati, S. Masudy-Panah, S.T. Chua, M. Sharma, T.I. Wong, H.R. Tan, D. Chi, Color tunable low cost transparent heat reflector using copper and titanium oxide for energy saving application, Scientific reports, 6 (2016).

[11] J. Wang, Q. Li, Q.-Y. Xiang, J.-L. Cao, Performances of AIN coatings as hydrogen isotopes permeation barriers, Fusion Engineering and Design, 102 (2016) 94-98.

[12] J.S. Becker, S. Suh, S. Wang, R.G. Gordon, Highly conformal thin films of tungsten nitride prepared by atomic layer deposition from a novel precursor, Chemistry of materials, 15 (2003) 29692976. 
[13] L. Rebouta, A. Sousa, M. Andritschky, F. Cerqueira, C.J. Tavares, P. Santilli, K. Pischow, Solar selective absorbing coatings based on AISiN/AISiON/AlSiO y layers, Applied Surface Science, 356 (2015) 203-212.

[14] J. Jyothi, H. Chaliyawala, G. Srinivas, H.S. Nagaraja, H.C. Barshilia, Design and fabrication of spectrally selective TiAIC/TiAICN/TiAISiCN/TiAISiCO/TiAISiO tandem absorber for high-temperature solar thermal power applications, Solar energy materials and solar cells, 140 (2015) 209-216. 


\begin{tabular}{c}
\hline $\mathbf{A l}_{\mathbf{2}} \mathbf{O}_{\mathbf{3}}$ (Dielectric) \\
\hline WAION (Metal-dielectric composite) \\
\hline WAIN (Metal-dielectric composite) \\
\hline W (IR reflector) \\
\hline Stainless steel (Substrate)
\end{tabular}

Fig. 1. Schematic of the design of W/WAlN/WAlON/ $\mathrm{Al}_{2} \mathrm{O}_{3}$-based solar selective absorber coating 

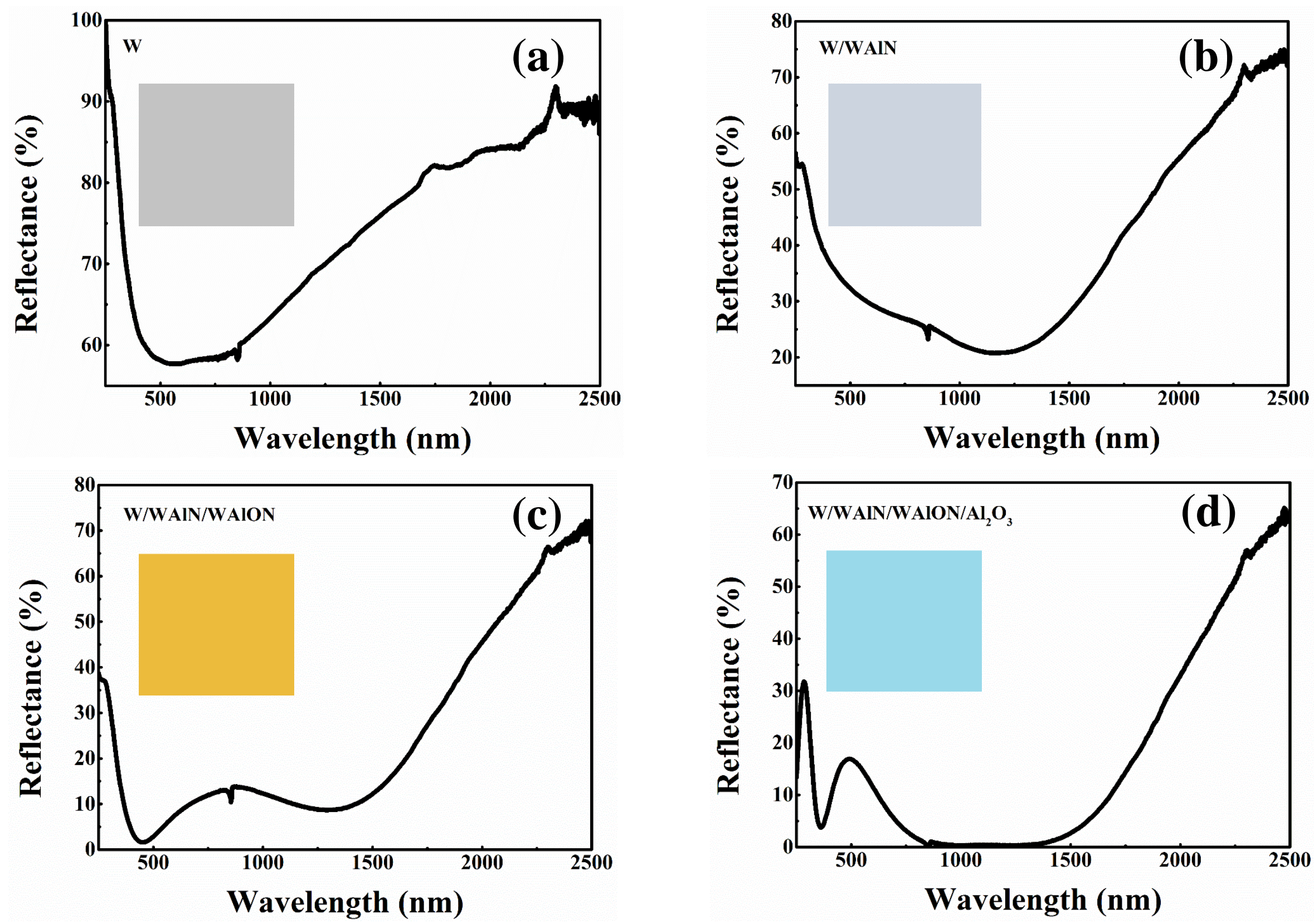

Fig. 2. Reflectance spectra of a) W; b) W/WAIN; c) W/WAIN/WAlON; d) W/WAIN/WAlON/Al $\mathrm{O}_{3}$ layer 


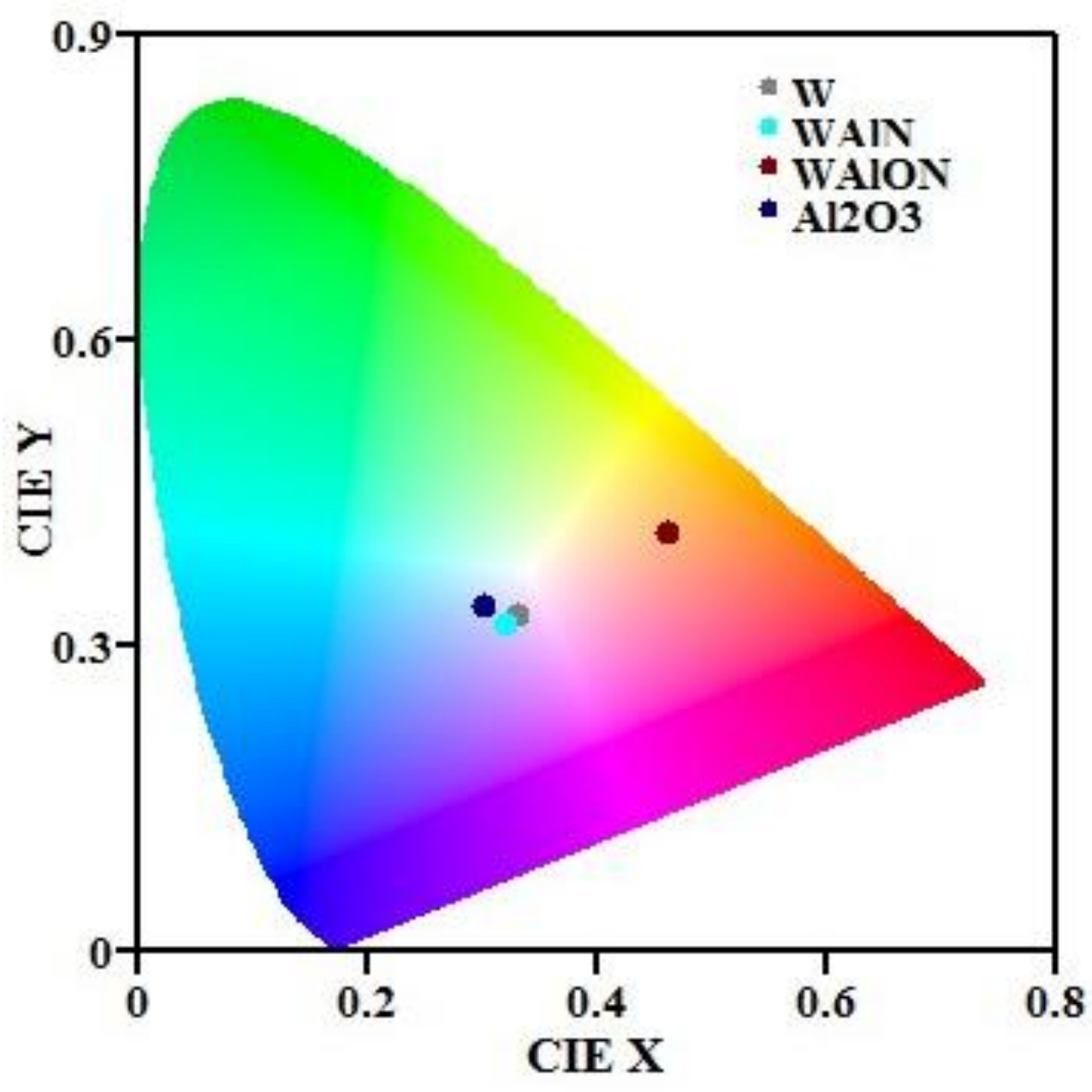

Fig. 3. Chromaticity diagram layer-added absorber coatings 


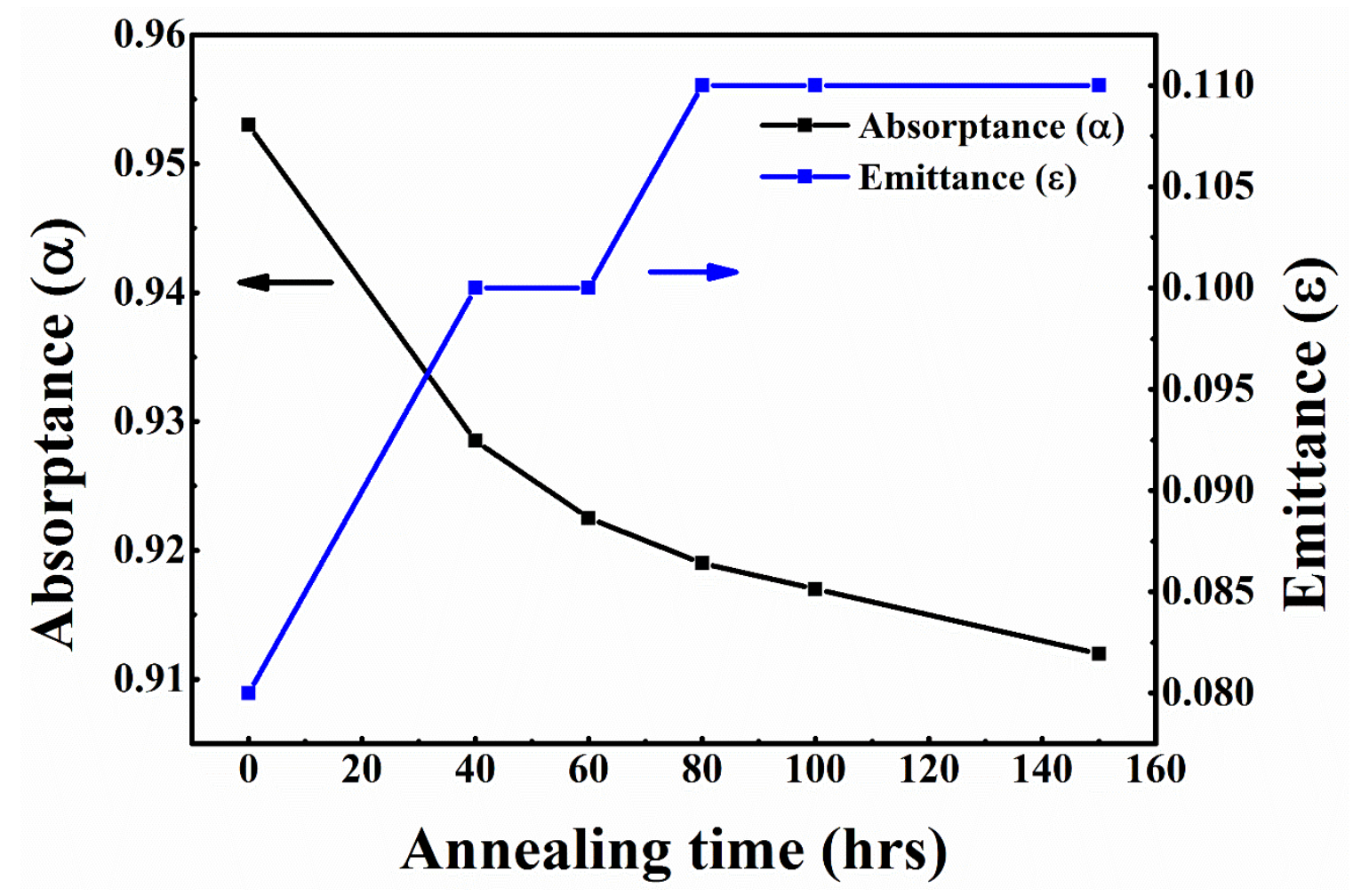

(a)

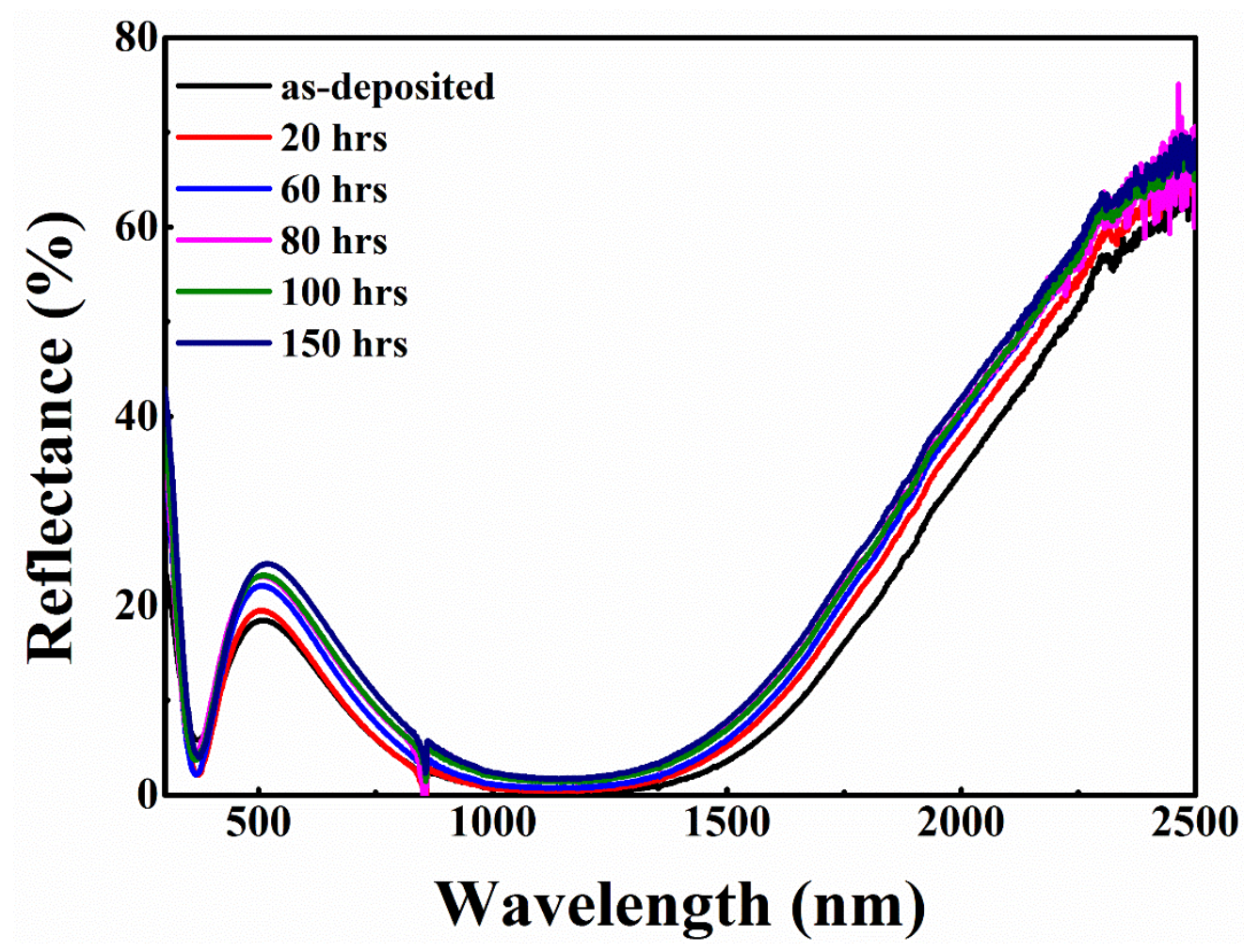

(b)

Fig. 4. a) Variation of absorptance and emittance value with respect to annealing duration;

b) Reflectance spectra of the as-deposited and heat treated coating at $500{ }^{\circ} \mathrm{C}$ in air for different time 


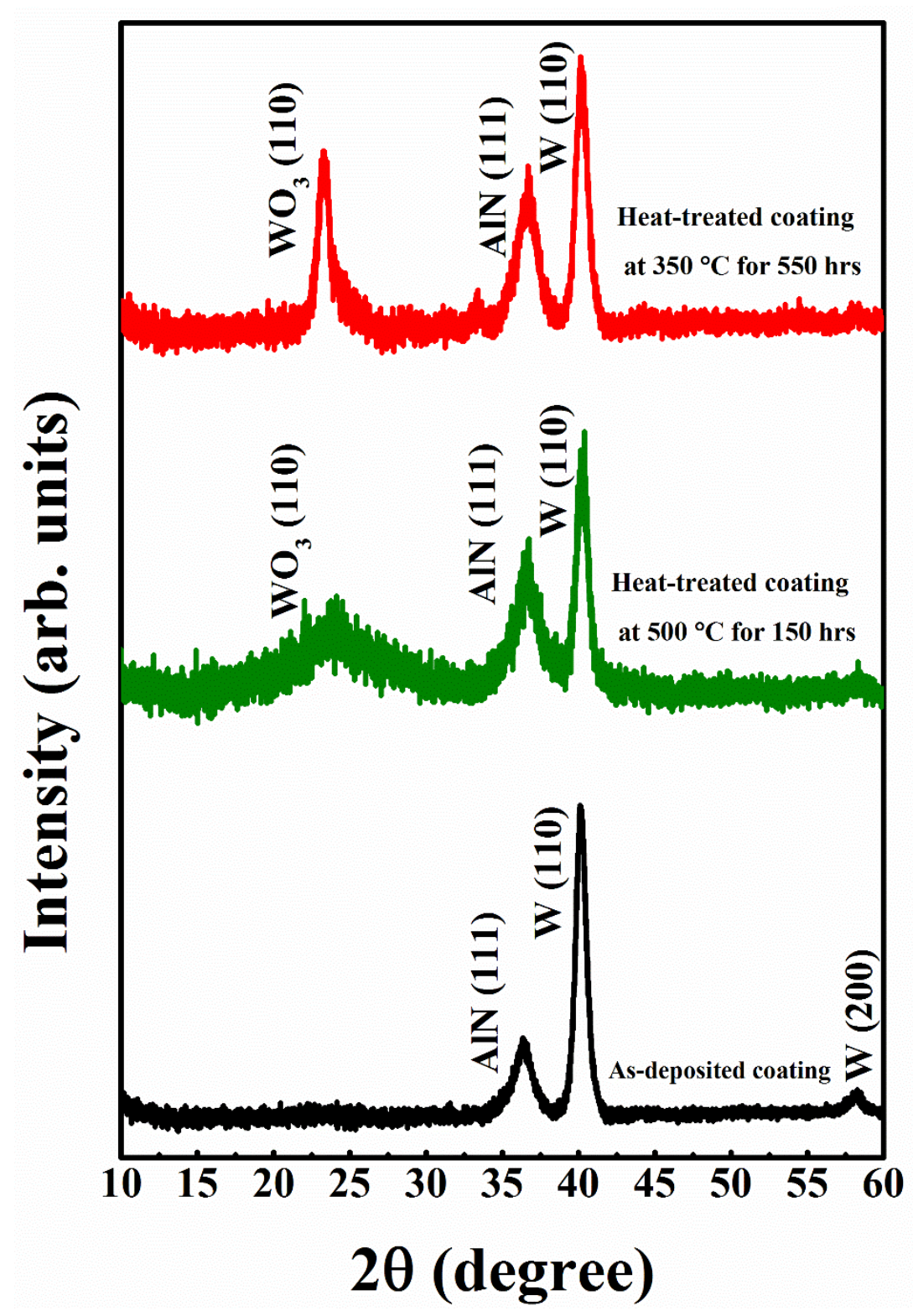

Fig. 5. XRD spectra of as-deposited and heat treated coatings 


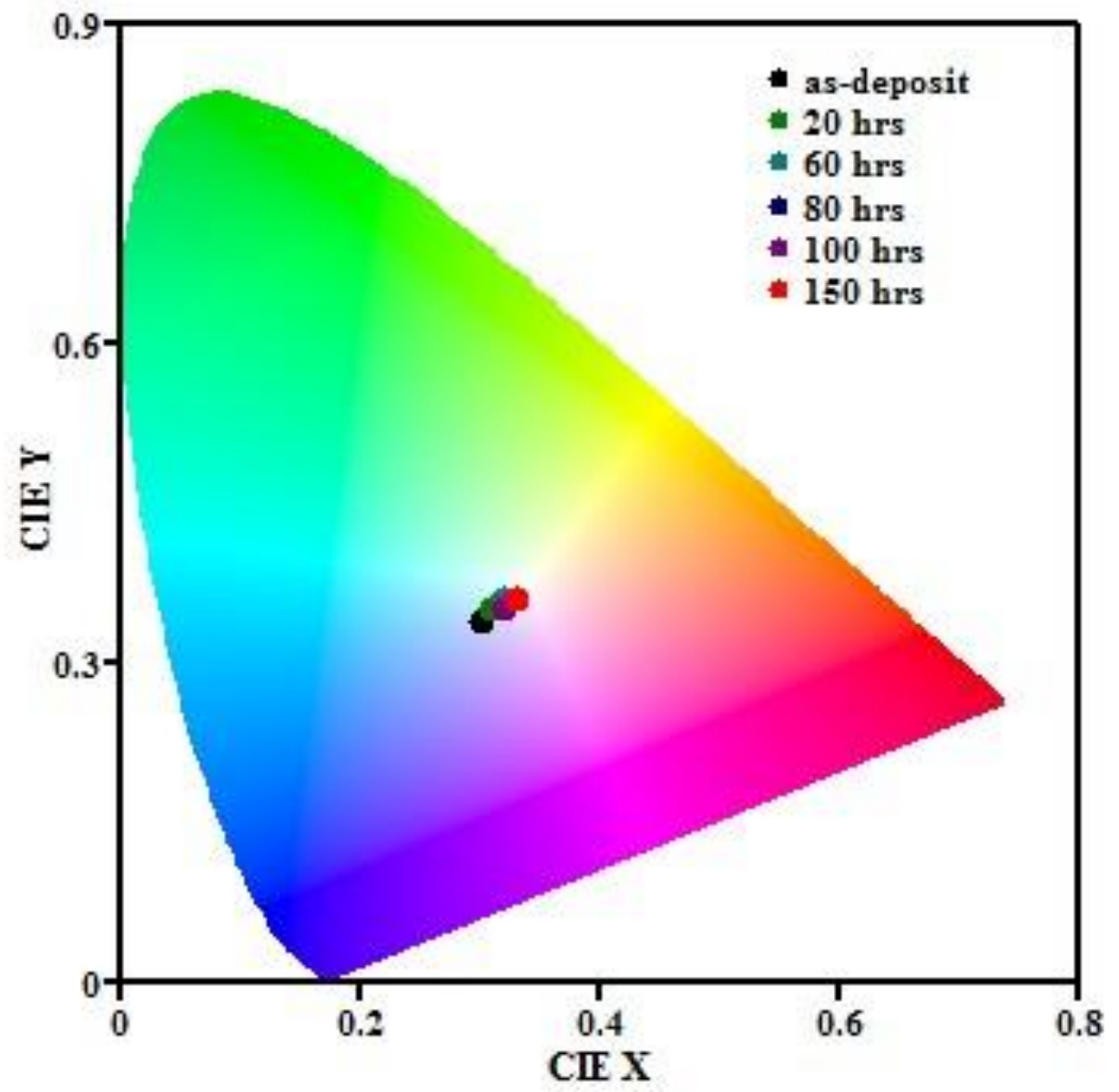

Fig. 6. Chromaticity diagram of as-prepared and heat-treated absorber coatings 


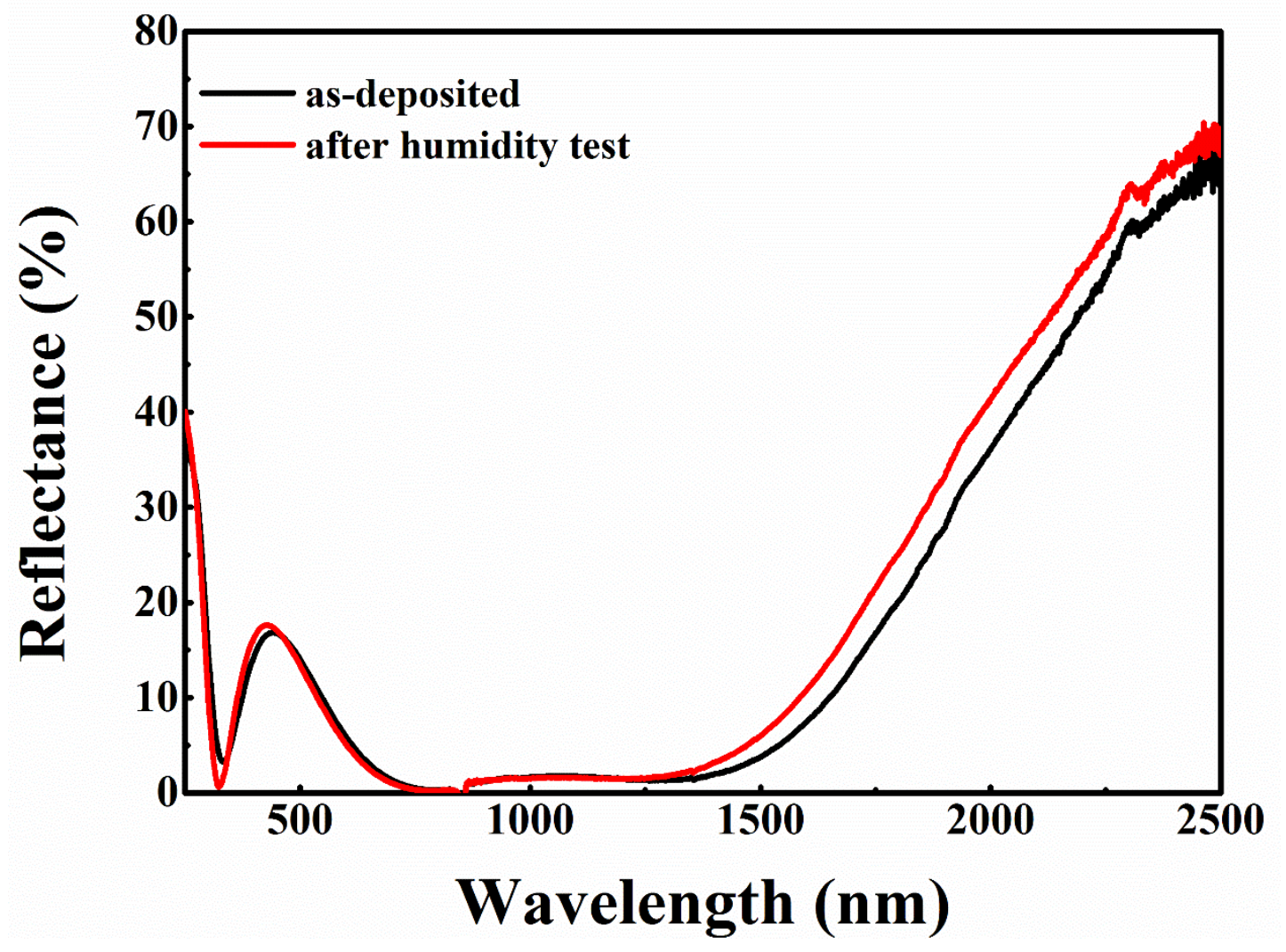

Fig. 7. Reflectance spectra of the coating before and after humidity test 